\title{
Effect of chloromethane on veratryl alcohol and lignin peroxidase production by the fungus Phanerochaete chrysosporium
}

\author{
David B. Harper, ${ }^{1,2 *}$ John A. Buswell ${ }^{3}$ and JAMes T. KenNedy ${ }^{2}$ \\ ${ }^{1}$ Department of Food and Agricultural Chemistry, The Queen's University of Belfast, Newforge Lane, \\ Belfast BT9 $5 P X, U K$ \\ ${ }^{2}$ Food and Agricultural Chemistry Research Division, Department of Agriculture for Northern Ireland, Newforge Lane, \\ Belfast BT9 5PX, UK \\ ${ }^{3}$ Department of Biology, Chinese University of Hong Kong, Shatin, New Territories, Hong Kong
}

(Received 15 April 1991; revised 2 August 1991; accepted 5 September 1991)

\begin{abstract}
Biosynthesis of veratryl alcohol, a secondary metabolite considered to be an important component of the lignindegrading system in the fungus Phanerochaete chrysosporium Burds INA-12, was initiated up to $36 \mathrm{~h}$ earlier in fungal cultures supplemented with 0.6 and $1.25 \mathrm{mM}-\mathrm{CH}_{3} \mathrm{Cl}$ compared with unsupplemented mycelia. Peak concentrations of the idiolyte were also about $70 \%$ higher in the presence of $0.6 \mathrm{mM}-\mathrm{CH}_{3} \mathrm{Cl}$, although peak levels elicited by $0.2,0.4$ and $1.25 \mathrm{mM}-\mathrm{CH}_{3} \mathrm{Cl}$ were lower than in unsupplemented cultures. Advanced initiation of veratryl alcohol biosynthesis in the presence of $\mathrm{CH}_{3} \mathrm{Cl}$ was reflected in the earlier appearance of lignin peroxidase (LiP) activity. This effect was most noticeable in cultures supplemented with 0.4 and $0.6 \mathrm{mM}-\mathrm{CH}_{3} \mathrm{Cl}$, where $\mathrm{LiP}$ was evident up to $24 \mathrm{~h}$ before detection in unsupplemented cultures. However, peak levels of LiP produced by $\mathrm{CH}_{3} \mathrm{Cl}$-augmented mycelia were always less - below $40 \%$ in the case of $1.25 \mathrm{mM}-\mathrm{CH}_{3} \mathrm{Cl}$ - than those recorded in cultures without supplementation. These effects may be explained by restricted metabolic availability of $\mathrm{CH}_{3} \mathrm{Cl}$ as methyl donor for veratryl alcohol biosynthesis in the early stages of fungal growth.
\end{abstract}

\section{Introduction}

Chloromethane $\left(\mathrm{CH}_{3} \mathrm{Cl}\right)$ is a gaseous natural product derived from methionine and released as a secondary metabolite by mycelia of many species of the Hymenochaetaceae, a widely distributed family of wood-rotting bracket fungi (Harper, 1985; Harper \& Kennedy, 1986; Harper \& Hamilton, 1988; Harper et al., 1988). Surprisingly, $\mathrm{CH}_{3} \mathrm{Cl}$ also appears to have a primary metabolic role in these species, acting as a methyl donor in the methylation of aromatic compounds such as benzoic and furoic acids (Harper et al., 1989; McNally et al., 1990). $\mathrm{A} \mathrm{CH}_{3} \mathrm{Cl}$-utilizing phenol methylating system has also been demonstrated in Phellinus pomaceus (Harper et al., 1989; McNally \& Harper, 1991).

Recently, $\mathrm{CH}_{3} \mathrm{Cl}$ was shown to be a methyl donor in the biosynthesis of veratryl (3,4-dimethoxybenzyl) alcohol in species of white-rot fungi belonging to other families such as the Corticaceae and Polyporaceae, none of which apparently emit detectable quantities of $\mathrm{CH}_{3} \mathrm{Cl}$ at any stage of growth (Harper et al., 1990). Thus Phanerochaete chrysosporium, Coriolus versicolor and

Abbreviation: LiP, lignin peroxidase.
Phlebia radiata incorporated high levels of $\mathrm{C}^{2} \mathrm{H}_{3}$ into the 3- and 4-O-methyl groups of veratryl alcohol when grown in the presence of $\mathrm{C}^{2} \mathrm{H}_{3} \mathrm{Cl}$. This observation led to the suggestion that a tightly channelled multi-enzyme system in which $\mathrm{CH}_{3} \mathrm{Cl}$ biosynthesis is closely coupled to $\mathrm{CH}_{3} \mathrm{Cl}$ utilization is present in such fungi, allowing $\mathrm{CH}_{3} \mathrm{Cl}$ to be used as methyl donor without any significant release of the compound to the external environment (Harper et al., 1990).

In $P$. chrysosporium, veratryl alcohol is a secondary metabolite (Lundquist \& Kirk, 1978) synthesized de novo via a pathway involving phenylalanine, 3,4-dimethoxycinnamyl alcohol and veratryl glycerol (Shimada et al., 1981). Veratryl alcohol has been reported to increase the level of ligninolytic enzymes in Phanerochaete chrysosporium (Faison \& Kirk, 1985; Faison et al., 1986; Leisola et al., 1984), and is a substrate for lignin peroxidase (LiP) which is a major component of the fungal ligninolytic system (Buswell \& Odier, 1987; Kirk \& Farrell, 1987; Tien, 1987). Veratryl alcohol also stimulates the oxidation of monomethoxylated aromatic compounds, such as anisyl alcohol, by LiP (Harvey et al., 1986). Monomethoxylated aromatics are normally poor substrates for the enzyme and it has been postulated that the idiolyte may 
act as a one-electron redox mediator in their oxidation and in lignin depolymerization (Harvey et al., 1986; Schoemaker et al., 1985). Other authors have proposed that veratryl alcohol counteracts inactivation of $\mathrm{LiP}$ by preventing the formation of lignin peroxidase Compound III (LiP III), an oxidized enzymic intermediate which is irreversibly inactivated in the presence of excess $\mathrm{H}_{2} \mathrm{O}_{2}$, and by converting LiP III back to the native enzyme (Haemmerli et al., 1986; Tonon \& Odier, 1988; Valli et al., 1990).

Harper et al. (1990) noted that veratryl alcohol biosynthesis during growth of $P$. chrysosporium appeared

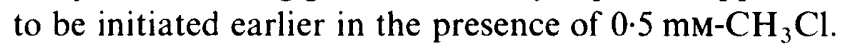
Additionally, LiP activity in the culture medium was apparently enhanced under these conditions. However, these changes seemed critically dependent on $\mathrm{CH}_{3} \mathrm{Cl}$ concentration and the nature of the relationship involved was not investigated systematically by these authors. The central role assigned to veratryl alcohol in lignin degradation renders the biosynthesis of the compound and its regulation of crucial importance. Consequently, in this paper we report a detailed examination of the effect of a range of $\mathrm{CH}_{3} \mathrm{Cl}$ concentrations on veratryl alcohol production and LiP activity at stages during growth of $P$. chrysosporium in an attempt to determine whether the metabolic availability of $\mathrm{CH}_{3} \mathrm{Cl}$ controls the onset of ligninolytic activity in cultures by reason of its effect on veratryl alcohol biosynthesis.

\section{Methods}

Organism and maintenance medium. Phanerochaete chrysosporium Burds INA-12 (CNCM I-398), previously utilized in investigations by Buswell et al. (1984) and Harper et al. (1990), was employed in the study.

Chemicals. Chloromethane was obtained from BDH and 3,4,5trimethoxybenzyl alcohol from Aldrich.

Culture medium and culture conditions. P. chrysosporium cultures were grown without agitation at $37^{\circ} \mathrm{C}$ in $100 \mathrm{ml}$ conical flasks in medium $(10 \mathrm{ml})$ containing $\left(\mathrm{g} \mathrm{l}^{-1}\right): \mathrm{KH}_{2} \mathrm{PO}_{4}(0 \cdot 2), \mathrm{MgSO}_{4} \cdot 7 \mathrm{H}_{2} \mathrm{O}(0 \cdot 05), \mathrm{NaCl}$ $(0.59), \mathrm{CaCl}_{2} \cdot 2 \mathrm{H}_{2} \mathrm{O}(0.013)$, thiamin $(0.0025)$, Difco yeast extract $(0.01)$, glycerol (10), L-asparagine monohydrate (1.0), $\mathrm{NH}_{4} \mathrm{NO}_{3}(0.5)$ and 2,2-dimethylsuccinic acid (1.46). The medium was supplemented with $1 \mathrm{ml}$ of trace element solution (Ander \& Eriksson, 1976) and the $\mathrm{pH}$ adjusted to $5 \cdot 0$ before filter sterilization. After inoculation of the medium with $5 \times 10^{5}$ conidia $1^{-1}$, prepared as described by Eriksson \& Johnsrud (1983), flasks were flushed with $100 \% \mathrm{O}_{2}$ for $2 \mathrm{~min}$ before being sealed with a polytetrafluoroethylene (PTFE)-coated rubber stopper. When the growth medium required supplementation with $\mathrm{CH}_{3} \mathrm{Cl}$ the following technique was used. From the PTFE-coated rubber stopper was suspended an aluminium clamp in which a Durham tube was fitted. Immediately before sealing the flasks, various volumes of aqueous $60 \mathrm{~mm}-\mathrm{CH}_{3} \mathrm{Cl}$ were pipetted into the tubes so as to establish a range of concentrations $(0.2,0.4,0.6$ and $1.25 \mathrm{~mm})$ in the culture media of the flasks after equilibration of the gaseous and aqueous phases (Harper et al., 1990).
Cultures (five replicates) grown in the presence of each $\mathrm{CH}_{3} \mathrm{Cl}$ concentration and also in the absence of the compound were harvested after periods of incubation ranging from 40-211 h. Mycelial dry weight, veratryl alcohol concentration and LiP activity in the culture supernatant are recorded as the mean of the five replicates. The entire experiment was repeated four times with similar results as regards the effects of $\mathrm{CH}_{3} \mathrm{Cl}$ on veratryl alcohol production and $\mathrm{LiP}$ activity although the absolute concentration of veratryl alcohol and LiP activity in the fungal culture medium tended to vary from experiment to experiment. The results given in the paper are of one representative experiment.

Determination of veratryl alcohol. Culture supernatant $(10 \mathrm{ml})$ after addition of 3,4,5-trimethoxybenzyl alcohol $\left(0.2 \mathrm{ml}\right.$ of a $500 \mathrm{~g} \mathrm{ml}^{-1}$ solution in acetone) as an internal standard was extracted with chloroform $(3 \times 15 \mathrm{ml})$ and the bulked extract was washed with saturated $\mathrm{NaCl}$ solution $(10 \mathrm{ml})$. The extract was dried over anhydrous $\mathrm{MgSO}_{4}$ and evaporated to $0.5 \mathrm{ml}$ under reduced pressure. Finally the solution was made up to $5 \mathrm{ml}$ with diethyl ether.

The extracts were analysed by gas chromatography-mass spectrometry using the conditions described by Harper et al. (1990). Veratryl alcohol was quantified by comparison of the ion current at $m / e 168$ at the retention time of veratryl alcohol with a calibration graph prepared using solutions containing known concentrations of the compound. Ion current at $m / e 198$ produced by trimethoxybenzyl alcohol, the internal standard, was also monitored so as to allow correction for recovery.

LiP assay. The activity of LiP in culture supernatants was determined by measuring the increase in absorbance at $310 \mathrm{~nm}$ due to oxidation of veratryl alcohol to veratraldehyde in the presence of $\mathrm{H}_{2} \mathrm{O}_{2}$ (Tien \& Kirk, 1984). In the assay, supernatant (1 ml) was incubated with $4 \mathrm{~mm}$-veratryl alcohol and $0.27 \mathrm{~mm}-\mathrm{H}_{2} \mathrm{O}_{2}$ in $60 \mathrm{~mm}$-sodium tartrate buffer, $\mathrm{pH} 3.0$, at $37^{\circ} \mathrm{C}$. Activities are expressed as nmol veratraldehyde formed $\min ^{-1}(\mathrm{ml} \text { culture medium })^{-1}$.

Assessment of growth. Mycelial growth was measured at various stages of incubation as the weight of mycelia harvested by filtration and dried at $100^{\circ} \mathrm{C}$.

\section{Results and Discussion}

Mycelial growth, veratryl alcohol concentration and LiP activity in the culture medium were measured at stages during growth of $P$. chrysosporium at a range of concentrations between 0 and $1.25 \mathrm{~mm}-\mathrm{CH}_{3} \mathrm{Cl}$. For the sake of clarity and to aid interpretation, a comparison of the effects of only two $\mathrm{CH}_{3} \mathrm{Cl}$ concentrations on these parameters is shown in Fig. $1(a, b, c)$.

Although a slightly higher growth yield was observed in the presence of $0.6 \mathrm{mM}^{-} \mathrm{CH}_{3} \mathrm{Cl}(P<0.05$ for final growth weight in the presence of $0.6 \mathrm{mM}-\mathrm{CH}_{3} \mathrm{Cl}$ compared with that in the absence of the compound), $\mathrm{CH}_{3} \mathrm{Cl}$ had little effect on the general pattern of fungal growth (Fig. 1a). However, even this small difference in final growth weight became statistically insignificant when the concentration of $\mathrm{CH}_{3} \mathrm{Cl}$ was increased to $1.25 \mathrm{mM}$. Nevertheless, it is clear that veratryl alcohol production (Fig. $1 b$ ) was initiated about $36 \mathrm{~h}$ earlier in mycelia grown in the presence of both 0.6 and $1.25 \mathrm{~mm}-\mathrm{CH}_{3} \mathrm{Cl}$ than in mycelia cultured in unsupplemented media. With 

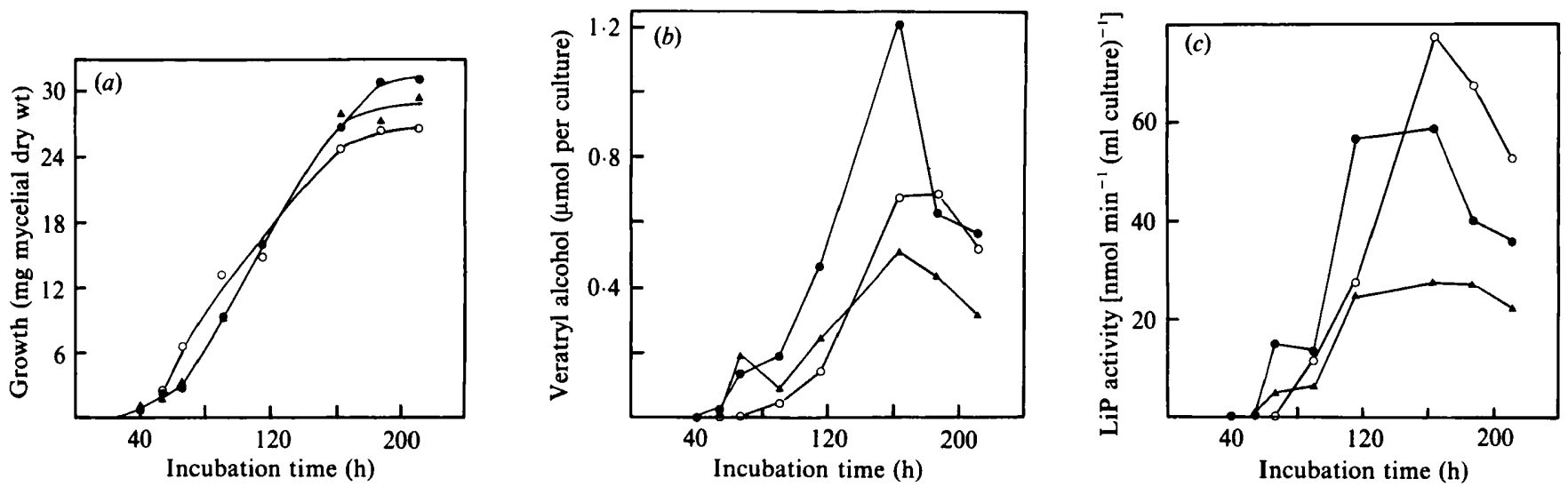

Fig. 1. Effects of 0.6 and $1.25 \mathrm{mM}-\mathrm{CH}_{3} \mathrm{Cl}$ on $(a)$ growth, $(b)$ veratryl alcohol concentration and $(c)$ LiP activity during growth of $P$. chrysosporium INA-12. Cultures of $P$. chrysosporium INA-12 were grown at $37^{\circ} \mathrm{C}$ in $100 \mathrm{ml}$ conical flasks containing glycerol high nitrogen medium $(10 \mathrm{ml})$ under $100 \% \mathrm{O}_{2}$ in the presence of $0,0.6$ and $1.25 \mathrm{mM}-\mathrm{CH}_{3} \mathrm{Cl}$. At intervals during growth, the contents of five replicate flasks of each treatment were harvested individually for measurement of mycelial dry weight, veratryl alcohol concentration and $\mathrm{LiP}$ activity. $\mathrm{O}, \mathrm{No} \mathrm{CH}_{3} \mathrm{Cl} ; 0,0.6 \mathrm{~mm}-\mathrm{CH}_{3} \mathrm{Cl} ; \Delta, 1.25 \mathrm{~mm}-\mathrm{CH}_{3} \mathrm{Cl}$.

$0.6 \mathrm{mM}-\mathrm{CH}_{3} \mathrm{Cl}$, this enhanced production was maintained at all stages of growth up to $163 \mathrm{~h}(P<0.05$ for comparison of veratryl alcohol concentration in the presence of $0.6 \mathrm{mM}-\mathrm{CH}_{3} \mathrm{Cl}$ with that in its absence after incubation periods of 90,115 and $163 \mathrm{~h}$, and $P<0.1$ for incubation period $66 \mathrm{~h}$ ). A maximum veratryl alcohol concentration of $1.2 \mu \mathrm{mol}$ per culture was attained at $163 \mathrm{~h}$, considerably in excess of the maximum of $0.7 \mu \mathrm{mol}$ per culture achieved in the absence of $\mathrm{CH}_{3} \mathrm{Cl}$. Despite the earlier induction of veratryl alcohol biosynthesis manifested by cultures grown in the presence of

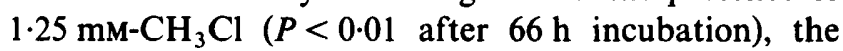
increased concentration of the compound relative to that in the unsupplemented medium did not persist in the later stages of growth; indeed, the maximum level of veratryl alcohol observed was significantly less than that in the unsupplemented medium $(P<0.1$ after $163 \mathrm{~h}$ incubation).

Veratryl alcohol concentrations after $90 \mathrm{~h}$ and $163 \mathrm{~h}$ for cultures incubated at each $\mathrm{CH}_{3} \mathrm{Cl}$ concentration are compared with those for unsupplemented cultures in Fig. 2. It is evident from the $90 \mathrm{~h}$ values that $\mathrm{CH}_{3} \mathrm{Cl}$ concentrations between 0.2 and $0.6 \mathrm{mM}$ caused initiation of veratryl alcohol biosynthesis at an earlier stage of growth. However, this stimulation did not result in significantly higher veratryl alcohol concentrations at $163 \mathrm{~h}$ except in the case of $0.6 \mathrm{mM}-\mathrm{CH}_{3} \mathrm{Cl}$, where the mean veratryl alcohol level in the culture medium was $70 \%$ greater than in the unsupplemented medium.

From Fig. $1(c)$ and Fig. 3, it is apparent that the earlier initiation of veratryl alcohol biosynthesis in the presence of $\mathrm{CH}_{3} \mathrm{Cl}$ is mirrored by an earlier induction of $\mathrm{LiP}$ activity. This effect is particularly marked in cultures supplemented with 0.4 and $0.6 \mathrm{mM}-\mathrm{CH}_{3} \mathrm{Cl}$, where $\mathrm{LiP}$

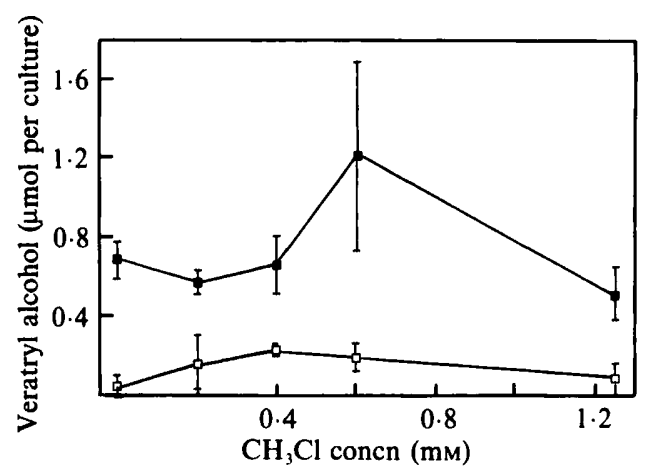

Fig. 2. Effect of $\mathrm{CH}_{3} \mathrm{Cl}$ concentration on veratryl alcohol concentration in the culture medium after 90 and $163 \mathrm{~h}$ growth of $P$. chrysosporium INA-12. After growth of $P$. chrysosporium INA-12 at a range of $\mathrm{CH}_{3} \mathrm{Cl}$ concentrations and harvesting as described in Fig. 1, veratryl alcohol concentrations were determined in each of five replicate cultures as described in Methods. Values given are means \pm SD. $\square$, Veratryl alcohol concentration after $90 \mathrm{~h}$ growth; $\square$, veratryl alcohol concentration after $163 \mathrm{~h}$ growth.

production begins approximately $24 \mathrm{~h}$ ahead of that in unsupplemented cultures $(P<0.01$ for comparison of LiP activity in the presence of $0.6 \mathrm{mM}-\mathrm{CH}_{3} \mathrm{Cl}$ with that in its absence after $66 \mathrm{~h}$ incubation, and $P<0 \cdot 1$ after $115 \mathrm{~h} ; P<0.05$ for comparison of LiP activity in the presence of $0.4 \mathrm{~mm}-\mathrm{CH}_{3} \mathrm{Cl}$ with that in its absence after $90 \mathrm{~h}$ incubation, and $P<0.01$ at $115 \mathrm{~h}$ ). Earlier production of $\mathrm{LiP}$ in the presence of $\mathrm{CH}_{3} \mathrm{Cl}$ does not seem to be associated with the eventual attainment of higher maximum activity. On the contrary, peak values for LiP activity in cultures grown in the presence of $\mathrm{CH}_{3} \mathrm{Cl}$ are somewhat less than those recorded in the unsupple- 


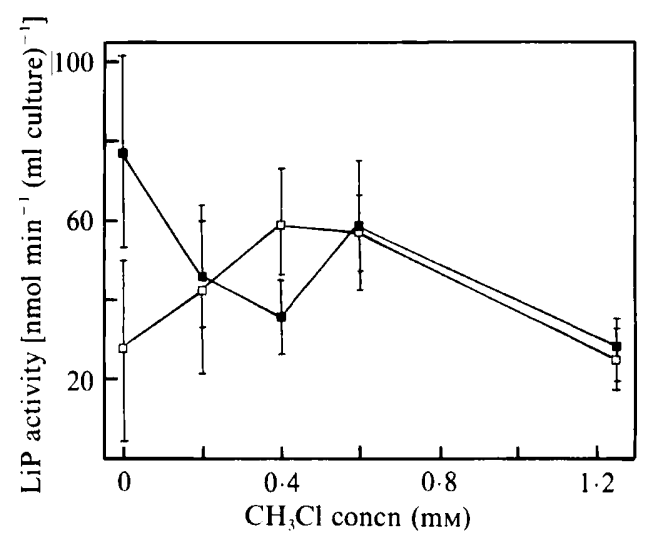

Fig. 3. Effect of $\mathrm{CH}_{3} \mathrm{Cl}$ concentration on LiP activity in the culture medium after 115 and $163 \mathrm{~h}$ growth of $P$. chrysosporium INA-12. After growth of $P$. chrysosporium INA-12 at a range of $\mathrm{CH}_{3} \mathrm{Cl}$ concentrations and harvesting as described in Fig. 1, LiP activities were determined in each of five replicate cultures as described in Methods. Values given are means \pm SD. $\square$, LiP activity after $115 \mathrm{~h}$ growth; $\square$, LiP activity after $163 \mathrm{~h}$ growth.

mented cultures. This inhibition is particularly significant in cultures grown in the presence of $1.25 \mathrm{mM}-\mathrm{CH}_{3} \mathrm{Cl}$ $(P<0.01$ after 163 and $187 \mathrm{~h}$ incubation and $P<0.05$ at $211 \mathrm{~h}$ incubation), which showed a peak level of enzyme activity less than $30 \%$ of that of the unsupplemented cultures.

Lignin peroxidase production by $P$. chrysosporium INA-12 grown on glycerol is considerably higher than the enzyme levels reported for other more-studied strains of the fungus, including $P$. chrysosporium ME-446 (ATCC 34541) from which LiP was originally isolated. Moreover, whereas enzyme synthesis in these strains is repressed by high nitrogen, $P$. chrysosporium INA-12 produces LiP under conditions of nutrient nitrogen sufficiency. The high levels of LiP observed when glycerol serves as carbon source may be related to the relatively poor growth rate of $P$. chrysosporium INA-12 on this compound which essentially mimics the nutritional status of carbon limitation. More recently, several other strains of $P$. chrysosporium which grew poorly on glycerol were shown to produce high titres of LiP (Roch et al., 1989). The triggering of secondary metabolism in $P$. chrysosporium, and hence the onset of ligninolysis and LiP synthesis, by carbon limitation is now welldocumented (Keyser et al., 1978; Jeffries et al., 1981; Faison \& Kirk, 1985).

Poor fungal growth on glycerol may also account for the results shown in Fig. $1(a, b)$ where production of the secondary metabolite, veratryl alcohol, apparently follows primary metabolite kinetics. Secondary metabolites are often defined as compounds produced after growth has ceased or in the absence of growth. However, many examples are documented involving other micro-organ- isms where production of a secondary metabolite occurs during exponential phase growth, either when a relatively poor source of carbon is used for growth during batch culture or in steady state cultures in the chemostat (Demain et al., 1979). The observed decrease in veratryl alcohol levels after $163 \mathrm{~h}$ probably reflects a high rate of turnover of this compound in the culture medium (Harper et al., 1990; Leisola et al., 1985). This is consistent with the key metabolic roles assigned to the metabolite (Buswell \& Odier, 1987).

In summary, it would appear that $0.6 \mathrm{~mm}-\mathrm{CH}_{3} \mathrm{Cl}$ causes induction of both veratryl alcohol biosynthesis and LiP at an earlier stage of fungal growth than would normally be the case, although only veratryl alcohol reaches a peak value higher than that in the unsupplemented medium. Higher concentrations of $\mathrm{CH}_{3} \mathrm{Cl}$, i.e. $1.25 \mathrm{~mm}-\mathrm{CH}_{3} \mathrm{Cl}$, whilst causing a similar advancement of veratryl alcohol and LiP production to an earlier stage of growth, lead to a marked depression in the veratryl alcohol concentrations and LiP activities achieved at later stages of growth. The critical dependence of these effects on the exact $\mathrm{CH}_{3} \mathrm{Cl}$ concentration explains the somewhat variable results reported by Harper et al. (1990).

The broadly parallel effects of $\mathrm{CH}_{3} \mathrm{Cl}$ on both veratryl alcohol biosynthesis and LiP activity are in accord with the proposal that veratryl alcohol production is closely linked with LiP activity and ligninolysis in P. chrysosporium (Faison \& Kirk, 1985; Leisola et al., 1984). Veratryl alcohol production and the appearance of ligninolysis in this fungus share several common features. Both appear at the onset of idiophase triggered by either nitrogen or carbon limitation (Keyser et al., 1978; Jeffries et al., 1981), are enhanced by elevated oxygen concentrations (Shimada et al., 1981), and are suppressed by culture agitation (Shimada et al., 1981). Gold et al. (1982) have also described mutant and revertant strains of $P$. chrysosporium in which lignin decomposition and veratryl alcohol biosynthesis are coupled, although this relationship apparently does not exist in other mutants (Liwicki et al., 1985). Veratryl alcohol is also ranked among the most effective of several lignin substructure molecules which elicit elevated levels of LiP, although addition of exogenous idiolyte alone to growing (trophophasic) cultures of $P$. chrysosporium failed to elicit the earlier appearance of either LiP or the complete ligninolytic system (lignin $\rightarrow \mathrm{CO}_{2}$ ) (Faison \& Kirk, 1985). Similar stimulatory effects on LiP levels have subsequently been observed in several other white-rot fungi (Phlebia radiata, Coriolus versicolor, Merulius tremellosus, Pleurotus ostreatus and Chrysosporium pruinosum) that produce extracellular peroxidases resembling the LiP of $P$. chrysosporium (Hatakka et al., 1987; Waldner et al., 1986; Biswas-Hawkes et al., 1987). However, 
although the ligninolytic system is considered to be inducible (Ulmer et al., 1984; Faison et al., 1986), increases in LiP mRNA or in translation of the $\mathrm{LiP}$ protein have yet to be directly attributed to veratryl alcohol (Tien, 1987).

The mechanism by which $\mathrm{CH}_{3} \mathrm{Cl}$ affects veratryl alcohol biosynthesis is unknown, but it is possible that the rate of methylation of postulated veratryl alcohol precursors such as caffeic and ferulic acids may be restricted by the metabolic availability of $\mathrm{CH}_{3} \mathrm{Cl}$ as methyl donor in the early stages of growth so limiting veratryl alcohol biosynthesis.

\section{References}

ANDER, P. \& ERIXsson, K.-E. (1976). The importance of phenol oxidase activity in lignin degradation by the white rot fungus Sporotrichum pulverulentum. Archives of Microbiology 109, 1-8.

Biswas-Hawkes, D., Dodson, A. P. J., HaRvey, P. J. \& Palmer, J. M. (1987). Ligninases from white-rot fungi. In Lignin Enzymic and Microbial Degradation, pp. 125-130. Edited by E. Odier. Paris: INRA Publications.

Buswell, J. A. \& ODIER, E. (1987). Lignin biodegradation. $C R C$ Critical Reviews of Biotechnology 6, 1-60.

Buswell, J. A., Mollet, B. \& Odier, E. (1984). Ligninolytic enzyme production by Phanerochaete chrysosporium under conditions of nitrogen sufficiency. FEMS Microbiology Letters 25, 295-299.

Demain, A. L., KenNel, Y. M. \& Aharonowitz, Y. (1979). Microbial technology: current state, future prospects. Symposia of the Society for General Microbiology 29, 163-165.

ERIKSSON, K.-E. \& JoHNSRUd, S. C. (1983). Mutants of the white-rot fungus Sporotrichum pulverulentum with increased cellulase and $\beta$-Dglucosidase production. Enzyme and Microbial Technology 5, 425429.

FAISON, B. D. \& KIRK, T. K. (1985). Factors involved in the regulation of ligninase activity in Phanerochaete chrysosporium. Applied and Environmental Microbiology 49, 299-304.

FaISON, B. D., KIRK, T. K. \& FARRELL, R. L. (1986). Role of veratryl alcohol in regulating ligninase activity in Phanerochaete chrysosporium. Applied and Environmental Microbiology 52, 251-254.

Gold, M. H., Mayfield, M. B., Chang, T. M., Krisnangkura, K., Shimada, M., Enoki, Á. \& GlenN, J. K. (1982). A Phanerochaete chrysosporium mutant defective in lignin degradation as well as several other secondary metabolic functions. Archives of Microbiology 132, 115-122.

Haemmerli, S. D., Leisola, M. S. A., Sanglard, D. \& Fiechter, A. (1986). Oxidation of benzo(a)pyrene by extracellular ligninases of Phanerochaete chrysosporium. Journal of Biological Chemistry 261, 6900-6903.

HARPER, D. B. (1985). Halomethane from halide ion - a highly efficient fungal conversion of environmental significance. Nature, London $315,55-57$.

HaRper, D. B \& Hamilton, J. T. G. (1988). Biosynthesis of chloromethane in Phellinus pomaceus. Journal of General Microbiology 134, 2831-2839.

HARPER, D. B. \& KENNEDY, J. T. (1986). Effect of growth conditions on halomethane production by Phellinus species: biological and environmental implications. Journal of General Microbiology 132 , $1231-1246$

HARPER, D. B., KenNedy, J. T. \& Hamilton, J. T. G. (1988) Chloromethane biosynthesis in poroid fungi. Phytochemistry 27, $3147-3153$
Harper, D. B., Hamilton, J. T. G., Kennedy, J. T. \& MCNally, K. J. (1989). Chloromethane, a novel methyl donor for biosynthesis of esters and anisoles in Phellinus pomaceus. Applied and Environmental Microbiology 55, 1981-1989.

Harper, D. B., Buswell, J. A., Kennedy, J. T. \& Hamilton, J. T. G. (1990). Chloromethane; methyl donor in veratryl alcohol biosynthesis in Phanerochaete chrysosporium and other lignin degrading fungi. Applied and Environmental Microbiology 56, 3450-3457.

Harvey, P. J., Schoemaker, H. E. \& Palmer, J. M. (1986). Veratryl alcohol as a mediator and the role of radical cations in lignin biodegradation by Phanerochaete chrysosporium. FEBS Letters 195, 242-246.

HatakKa, A., Kantelinen, A., Tervila-Wilo, A. \& ViIKari, L. (1987). Production of ligninases by Phlebia radiata in agitated cultures. In Lignin Enzymic and Microbial Degradation, pp. 185-189. Edited by E. Odier, Paris: INRA Publications.

Jeffries, T. W., ChOI, S. \& KIRK, T. K. (1981). Nutritional regulation of lignin degradation by Phanerochaete chrysosporium. Applied and Environmental Microbiology 129, 321-324.

Keyser, P., KIRK, T. K. \& ZeIKUS, J. G. (1978). Ligninolytic enzyme system of Phanerochaete chrysosporium: synthesis in the absence of lignin in response to nitrogen starvation. Journal of Bacteriology 135 , 790-797.

KIRK, T. K. \& FARRelL, R. L. (1987). Enzymatic 'combustion'; The microbial degradation of lignin. Annual Review of Microbiology 41, 465-505.

Leisola, M. S. A., Schmidt, B., Thanei-Wyss, U. \& Fiechter, A. (1985). Aromatic ring cleavage of veratryl alcohol by Phanerochaete chrysosporium. FEMS Letters 189, 267-270.

Leisola, M. S. A., Ulmer, D. C., Waldner, R. \& Fiechter, A. (1984). Role of veratryl alcohol in lignin degradation by Phanerochaete chrysosporium. Journal of Biotechnology 1, 331-339.

Liwicki, R., Paterson, A., MacDonald, M. J. \& Broda, P. (1985). Phenotypic classes of phenoloxidase-negative mutants of the lignindegrading fungus Phanerochaete chrysosporium. Journal of Bacteriology 162, 641-644.

LUNDQUIST, K. \& KIRK, T. K. (1978). De novo synthesis and decomposition of veratryl alcohol by a lignin-degrading basidiomycete. Phytochemistry 17, 1676.

MCNally, K. J. \& HaRPeR, D. B. (1991). Methylation of phenol by chloromethane in the fungus Phellinus pomaceus. Journal of General Microbiology 137, 1029-1032.

McNally, K. J., Hamilton, J. T. G. \& Harper, D. B. (1990). The methylation of benzoic and n-butyric acids by chloromethane in Phellinus pomaceus. Journal of General Microbiology 136, 1509-1515.

Roch, P., Buswell, J. A., CAIN, R. B. \& Odier, E. (1989). Lignin peroxidase production by strains of Phanerochaete chrysosporium grown on glycerol. Applied Microbiology and Biotechnology 31, 587591

Schoemaker, H. E., Harvey, P. J., Bowen, R. M. \& Palmer, J. M. (1985). On the mechanism of enzymatic lignin breakdown. FEBS Letters 183, 7-12

Shimada, M., Nakatsubo, F., Kirk, T. K. \& Higuchi, T. (1981). Biosynthesis of the secondary metabolite veratryl alcohol in relation to lignin degradation in Phanerochaete chrysosporium. Archives of Microbiology 129, 321-324.

TIEN, M. (1987). Properties of ligninase from Phanerochaete chrysosporium and their possible applications. CRC Critical Reviews of Microbiology 15, 141-168.

TIEN, M. \& KIRK, T. K. (1984). Lignin degrading enzyme from Phanerochaete chrysosporium. Purification, characterization and catalytic properties of a unique $\mathrm{H}_{2} \mathrm{O}_{2}$-requiring oxygenase. Proceedings of the National Academy of Sciences of the United States of America 81, 2280-2284.

TONON, F. \& ODIER, E. (1988). Influence of veratryl alcohol and hydrogen peroxide on ligninase activity and ligninase production by Phanerochaete chrysosporium. Applied and Environmental Microbiology 54, 466-472.

Ulmer, D. C., Leisola, M. S. A. \& Fiechter, A. (1984). Possible reduction of the ligninolytic system of Phanerochaete chrysosporium. Journal of Biotechnology 1, 13-24. 
Valli, V., WaRnshl, H. \& Gold, M. H. (1990). Oxidation of monomethoxylated aromatic compounds by lignin peroxidase: role of veratryl alcohol in lignin biodegradation. Biochemistry 29, 85358539.
WALDner, R., Leisola, M. \& Fiechter, A. (1986). Production of extracellular ligninolytic enzymes by different white-rot fungi. Proceedings of the 3rd International Conference (Stockholm) on Biotechnology in the Pulp and Paper Industry pp. 17-19. 